\title{
Determination of the Degree of Pasture Factor Digression in the Communities of Environment Contact Sites (Some Methodological Approaches)
}

\author{
Alexander P. Sizykh \\ Siberian Institute of Plant Physiology and Biochemistry of RAS SB, Irkutsk, Russia \\ Email: alexander.sizykh@gmail.com
}

How to cite this paper: Sizykh, A.P. (2016) Determination of the Degree of Pasture Factor Digression in the Communities of Environment Contact Sites (Some Methodological Approaches). Open Access Library Journal, 3: e3025.

http://dx.doi.org/10.4236/oalib.1103025

Received: September 1, 2016

Accepted: September 23, 2016

Published: September 27, 2016

Copyright $\odot 2016$ by author and Open Access Library Inc.

This work is licensed under the Creative

Commons Attribution International

License (CC BY 4.0).

http://creativecommons.org/licenses/by/4.0/

\begin{abstract}
This paper is concerning the problem of determining of the character of disturbance of plant communities under the influence of the pasture factors. There are methodological approaches for determining of the degrees of the digression of the plant communities based on qualitative and quantitative parameters of the structure of cenoses for different natural zones. However, there are no approaches and techniques for comprehensive (multifactor) assessment of the character of responses of vegetation to particular anthropogenic influences given the high contrast of the physico-geographical conditions of the territory. The paper discusses some results of preliminary comprehensive assessment of the disturbance of plant communities of the environment contact sites of the Baikal region as an example.
\end{abstract}

\section{Subject Areas}

Biogeography

\section{Keywords}

Plant Communities of the Environment Contact Sites, Influences of the Pasture Factor, The Degree of Digression

\section{Introduction}

Digression [1]-[6] is a directional deterioration of plant communities (and of ecosystems in a whole) under the impact of varying external (exoecodynamical, which means influences of the outside climate and ecotopological factors on the vegetation communities) or internal (endoecodynamical, which means changes of the ecotopes inside of the communities structure for different vegetation times and years as well) conditions for 
formation of a concrete phytocenosis, as well as of a system of conditions. Digression can progress up to catacenotic state [1], when a community (or an ecosystem in a whole) is being destroyed, and the return to a previous state is impossible.

Pasture factor digression is a variant of allogenic [1] [3] successions towards the decrease of species diversity, which results in simplifying of a plant community structure with selection of plant species, which are more resistant to the pasture factor impacts both of species and of communities in a whole by morphological and ecotypological characteristics. However, the pasture factor digression is not irreversible, and with elimination of impact pressure, a partial reconstruction of a community cenostructure is possible (by establishing of the pasture regimes for every sites of vegetation communities of the environment contact sites for example), although with other structuraldynamic and functional characteristics and properties. The process of a post-pasture reconstitution is a pasture demutation [2]. However, there are situations, when a pasture factor digression results in a fundamental change of an ecotope (habitat) of a community with generation of processes of further environment destruction, of such irreversible processes as erosion at steep slopes due to washing of soil horizons out.

Often a pasture factor digression promotes changes in communities' ecotopes resulting in leveling ("erosion") or in a shift of boundaries of environmental zones; this is especially characteristic for arid or semiarid regions as structure and dynamics of plant communities are unequal for different environmental zones. Due to this fact, taking into account of conditions and parameters determining a digression degree, it is quite linked with a concrete territory. i.e., plants species composition for one environmental zone (or a subzone, a height belt) may characterize any digression stage as in any other case the same plants species composition may reflect community dynamics for concrete environmental conditions and reflect only a character of pasture factor impacts.

\section{Discussion}

At present, there is no united approach in the determination of what is a stage of pasture digression-if these are dynamics of species composition under definite ecological conditions or changes in plants morphology, if this is a cenoses resistance or functioning type during a matter-energy exchange.

Which factors must be taken into account first of all while assessing the communities state-qualitative or quantitative parameters of their structure? The range of ecological amplitudes of plants species composing communities used as pasture factors is measured in orders of magnitude, and populations of concrete species can drastically differ by their requests to the environment during reconstitution in territorial and temporal terms, respectively. As environmental conditions determine in many aspects the species composition of communities, and ecotopes changes under the influence of pasture factors charge can induce in many cases the beginning of pasture digression, its stage or dimutation.

An important factor for determination of digression stage of a concrete community to be considered is phytocenosis state at observations start time taking into account the 
changes which occurred in a community before start of observations. This is often impossible. The community age consists of a set of ages of plants species composing a cenoses, of time for population renewal, of reconstitution time at any short-time changes variations in the community structure or dynamics resulting from changes of environmental factors (precipitations, temperature influencing vegetation periods time and duration) or of other anthropogenic factors.

Consequently, while determining stages of pasture factor digression, it is quite necessary to take into account all these factors, which are listed above, otherwise it is very probable to assess inconsiderable (or non-existing) changes in vegetation cover structure and as a result-an incorrect forecast of communities development under concrete environmental conditions will be done. It may be expressed as loss of a potential for probable reconstitution of pastures areas. A particular condition determining the representativity of a vegetation area in digression assessment is revealing of a dynamical state of communities during the observations-basic or serial community, demutation or ecological optimum state of plants species composition (edificators composition). There are other important factors: proective coverage, ratio of ecotypological groups of plants in the cenoses, total and specific productivity, phenological stages with consideration of precipitations and temperature dynamics under the conditions of pasture factors onto the communities [7].

Degression series are different for cenoses with different dominants composition (or by ecobiomorphs composition) differing by their response to animals pasturing impact. In some cases, it is possible to characterize a digression stage by the state of plants species, by the state of population of dominating plants species. This is often possible only by the character of a community cenotic structure in a whole. Nevertheless, a basic factor for the assessment of occurring changes in vegetation at pasture regime of its use is the genesis of vegetation cover of concrete territories under existing and varying conditions with a definite type (or form) of matter-energy exchange in the system reflecting a concrete phenomenon-a forest, a steppe, a forest-steppe or their transitional statesinterzonal, interheight belts, azonal, extrazonal ones [8].

\section{Conclusions}

The selection of concrete dominating factor(s), which will determine a digression degree in a community is a complicate task. Under rather stable environmental conditions and under anthropogenic impacts (e.g., pasturing), it is certainly difficult to establish a starting point for the assessment of digression stage in the communities of transitional environments. This requires many years of observations and other experimental approaches.

To determine the modern state of communities at pasture regime of use (often together with recreational charge), it is necessary to select an indicator usable for a comparative analysis with a "model" at least at first approximation. In our opinion, ecobiomorphological composition and quantitative ratio of plants species groups may serve as an initial point for determination of a stage of pasture factor digression of the 
vegetation under concrete physico-geographical conditions.

The initial information for the analysis of modern state of vegetation must be represented by the results of perennial studies of structural-dynamic organization of vegetation cover during different seasons in a concrete region taking into account the peculiarities of ecology of plant species composing a community. It is necessary as well to determine directions (progress or regress) in changes of communities' composition and structure. This will allow determining potential possibilities for reconstitution of communities, their productivity as one of indicators of phytocenoses digression. Hence, a long-term monitoring of all components in any plant community (and in a whole ecosystem), especially under the conditions of environments contact sites is necessary.

For future it is important to find the concrete of the regimes pasture using for concrete ecotopes and structure of the vegetation communities of the environment contact sites everywhere. It is possible for long time investigation because the changing climate takes place very fast.

\section{References}

[1] Shchukin, I.S. (1980) Four-Languages Encyclopaedia of Physical Geography Terms. Soviet Encyclopaedia, Moscow, 703 p.

[2] Reymers, N.F. (1990) Nature Management. Glossary, Mysl', Moscow, 639 p.

[3] Akzhigitov, G.N. (2000) English-Russian Ecological Dictionnary. Russkiy Yazyk, Moscow, $603 \mathrm{p}$.

[4] Sizykh, A.P. (2004) Current State of the Taiga-Steppe Communities of the Lake Baikal' Western Coast (Monitoring and Preservation Problem). Bulletin of Samara Scientific Center of Russian Academy of Sciences, 1, 94-101.

[5] Sizykh, A.P. (2006) Compositions and Spatial Changes of the Taiga-Steppe Communities Structure of the Lake Baikal' Western Coast. Siberian Ecology Journal, 2, 189-194.

[6] Sizykh, A.P. (2007) To Question about Digression of the Vegetation Communities of the Environment Contact Sites under Influences of the Anthropogenic Factors (Western Coast of Lake Baikal as an Example). Siberian Ecology Journal, 3, 441-447.

[7] Kasyanova, L.N. (1993) Ecology of Plants in Pre-Ol'khon Steppes. Nauka, Novosibirsk, 159 p.

[8] Sizykh, A.P. (2003) Cenostructure and Dynamical Trends of Taiga-Steppe Communities of Lake Baikal Western Coast. Vegetation Cover of Baikalian Siberia. ISU Publishing House, Irkutsk, 209-215. 
Submit or recommend next manuscript to OALib Journal and we will provide best service for you:

- Publication frequency: Monthly

- 9 subject areas of science, technology and medicine

- Fair and rigorous peer-review system

- Fast publication process

- Article promotion in various social networking sites (LinkedIn, Facebook, Twitter, etc.)

- Maximum dissemination of your research work

Submit Your Paper Online: Click Here to Submit

Or Contact service@oalib.com 